\title{
Contemporary outcomes of complete atrioventricular septal defect repair: Analysis of the Society of Thoracic Surgeons Congenital Heart Surgery Database
}

\author{
James D. St. Louis, MD, ${ }^{\mathrm{a}}$ Upinder Jodhka, MD, MHS, ${ }^{\mathrm{b}}$ Jeffrey P. Jacobs, MD, ${ }^{\mathrm{c}} \mathrm{Xia} \mathrm{He}, \mathrm{MS},{ }^{\mathrm{d}}$ \\ Kevin D. Hill, MD, ${ }^{\mathrm{d}}$ Sara K. Pasquali, MD, MHS, ${ }^{\mathrm{e}}$ and Marshall L. Jacobs, $\mathrm{MD}^{\mathrm{c}}$
}

\begin{abstract}
Objective: Contemporary outcomes data for complete atrioventricular septal defect (CAVSD) repair are limited. We sought to describe early outcomes of CAVSD repair across a large multicenter cohort, and explore potential associations with patient characteristics, including age, weight, and genetic syndromes.
\end{abstract}

\begin{abstract}
Methods: Patients in the Society of Thoracic Surgeons Congenital Heart Surgery Database having repair of CAVSD (2008-2011) were included. Preoperative, operative, and outcomes data were described. Univariate associations between patient factors and outcomes were described.

Results: Of 2399 patients (101 centers), 78.4\% had Down syndrome. Median age at surgery was 4.6 months (interquartile range, 3.5-6.1 months), with $11.8 \%(\mathrm{n}=284)$ aged $\leq 2.5$ months. Median weight at surgery was $5.0 \mathrm{~kg}$ (interquartile range, $4.3-5.8 \mathrm{~kg}$ ) with $6.3 \%(\mathrm{n}=151)<3.5 \mathrm{~kg}$. Pulmonary artery band removal at CAVSD repair was performed in 122 patients (4.6\%). Major complications occurred in $9.8 \%$, including permanent pacemaker implantation in $2.7 \%$. Median postoperative length of stay (PLOS) was 8 days (interquartile range, 5-14 days). Overall hospital mortality was 3.0\%. Weight $<3.5 \mathrm{~kg}$ and age $\leq 2.5$ months were associated with higher mortality, longer PLOS, and increased frequency of major complications. Patients with Down syndrome had lower rates of mortality and morbidities than other patients; PLOS was similar.
\end{abstract}

Conclusions: In a contemporary multicenter cohort, most patients with CAVSD have repair early in the first year of life. Prior pulmonary artery band is rare. Hospital mortality is generally low, although patients at extremes of low weight and younger age have worse outcomes. Mortality and major complication rates are lower in patients with Down syndrome. (J Thorac Cardiovasc Surg 2014;148:2526-31)

The natural history of complete atrioventricular septal defect (CAVSD) includes premature death due to complications of congestive heart failure and/or pulmonary artery hypertension. Repair during infancy is recommended for all patients. Outcomes following surgical repair have improved over several decades due to refinements of technique and postoperative management. ${ }^{1-7}$ The age for elective repair has steadily declined, from as late as 1 year a few decades ago to 3 to 6 months at most centers

From the Division of Pediatric Cardiac Surgery, ${ }^{\text {a }}$ Department of Surgery, and Department of Pediatrics, ${ }^{\mathrm{b}}$ University of Minnesota, Minneapolis, Minn; Division of Cardiac Surgery, ${ }^{c}$ Department of Surgery, Johns Hopkins School of Medicine, Baltimore, Md; Duke Clinical Research Institute, ${ }^{\mathrm{d}}$ Duke University School of Medicine, Durham, NC; and Department of Pediatrics and Communicable Diseases, ${ }^{\mathrm{e}}$ University of Michigan, Ann Arbor, Mich.

This work was supported by funding provided through the Society of Thoracic Surgeons.

Disclosures: Authors have nothing to disclose with regard to commercial support.

Read at the 60th Annual Meeting of the Southern Thoracic Surgical Association, Scottsdale, Arizona, November 2, 2013.

Received for publication April 16, 2014; revisions received May 12, 2014; accepted for publication May 29, 2014; available ahead of print Aug 12, 2014.

Address for reprints: James D. St. Louis, MD, East Building, 12th Fl, 2450 Riverside Ave, Minneapolis, MN 55454 (E-mail: stlou012@umn.edu).

$0022-5223 / \$ 36.00$

Copyright (c) 2014 by The American Association for Thoracic Surgery

http://dx.doi.org/10.1016/j.jtcvs.2014.05.095 today. ${ }^{6,8-12}$ Early repair is intended to minimize the risk of premature death or pulmonary vascular obstructive disease. There are, however, some patients with medically refractory congestive heart failure for whom repair even earlier in infancy must be considered, because the risk of adverse events during prolonged supportive medical therapy is substantial. Single-stage repair is generally preferred, but occasionally palliation with pulmonary artery banding $(\mathrm{PAB})$ is considered.

Although the benefits of surgical repair before age 6 months are now generally acknowledged, optimal timing is still debated and is unlikely to be the same for all patients. A recent study by Atz and the Pediatric Heart Network (PHN) Investigators ${ }^{9}$ reported outcomes of 120 patients who underwent repair of CAVSD at 7 centers. Adverse outcomes were negatively correlated with age at repair from birth to age 2.5 months, but did not vary by age beyond 2.5 months. There is a paucity of other multicenter studies addressing this issue.

CAVSD is frequently associated with Down syndrome. ${ }^{10}$ Associations between Down syndrome and contemporary outcomes remain to be established. Infants with Down syndrome and left-to-right shunts have long been believed to be susceptible to pulmonary vascular reactivity and respiratory complications. Despite these risks, our previous analysis of 


\section{Abbreviations and Acronyms \\ CAVSD = complete atrioventricular septal defect \\ IQR = interquartile range \\ $\mathrm{PAB}=$ pulmonary artery banding \\ PHN $=$ Pediatric Heart Network \\ PLOS = postoperative length of stay \\ STS-CHSD $=$ Society of Thoracic Surgeons \\ Congenital Heart Surgery Database}

multi-institutional data from the Society of Thoracic Surgeons Congenital Heart Surgery Database (STS-CHSD) showed that mortality rates for patients with or without Down syndrome did not differ significantly across the spectrum of pediatric cardiac surgical procedures. Lengths of stay were prolonged for patients with Down syndrome undergoing some specific procedures, but CAVSD repair was not one of those. ${ }^{13}$

Apart from the PHN study, ${ }^{9}$ there are no recent large multicenter studies pertaining to surgical outcomes among infants with CAVSD. The aim of our study is to provide a descriptive analysis of contemporary multicenter experience with repair of CAVSD using data from the STSCHSD.

\section{PATIENTS AND METHODS \\ Data Source}

The STS-CHSD contains operative, perioperative, and outcomes data on more than 250,000 patients undergoing congenital heart surgery since 1998, and currently includes information from 108 participating hospitals. Data quality and reliability are assured through intrinsic verification of data and a formal process of site visits and data audits. The Duke Clinical Research Institute serves as the data warehouse and analytic center for all of the STS National Databases. This analysis was approved by the Duke University Institutional Review Board, and by the STS Access and Publications Committee. This study was not considered human subjects research by the Duke University Institutional Review Board in accordance with the common rule (45 CFR 46.102(f)).

\section{Patient Population}

All STS-CHSD records from 2008 to 2011 with the procedure code for CAVSD repair entered for the index operation were identified. Patients with concomitant diagnosis of tetralogy of Fallot, total anomalous pulmonary venous connection, double outlet right ventricle, or any form of single ventricle (including single ventricle unbalanced antrioventricular canal or single ventricle heterotaxy syndrome) were excluded. Cases were analyzed on the basis of the first CAVSD operation of each admission. Patients with missing or invalid data for key variables were excluded.

\section{Data Collection}

Patient characteristics included age, weight, weight-for-age $z$-score, gender, race/ethnicity, additional preoperative factors (as defined by the STS-CHSD), noncardiac congenital anatomic abnormalities, chromosomal abnormalities or syndromes, and prior cardiac surgical procedures. Procedural factors include cardiopulmonary bypass, crossclamp times, and concurrent procedures.

\section{Outcomes}

The primary outcome was discharge mortality. Postoperative length of stay (PLOS) was calculated from date of operation to date of hospital discharge. Both the occurrence of any postoperative complication collected in the STS-CHSD, as well as major complications were evaluated. The latter include renal failure requiring dialysis, neurologic deficit persisting at discharge, arrhythmia requiring permanent pacemaker, mechanical circulatory support, phrenic nerve injury/paralyzed diaphragm, and unplanned reoperation/reintervention. ${ }^{14}$

\section{Analysis}

Distributions of patient characteristics and outcomes were summarized in the overall sample, in patients with Down syndrome and those without, as well as in patient groups defined by age and weight at surgery. Specifically, the age groups ( $\leq 2.5$ and $>2.5$ months) were defined based on findings previously reported by the PHN investigators ${ }^{9}$ and $3.5 \mathrm{~kg}$ was chosen as the threshold for low and high weight groups $(<3.5 \mathrm{~kg}$ and $\geq 3.5 \mathrm{~kg})$ after an initial exploration of discharge mortality by weight at surgery (Figure 1). In all groups, we reported the frequencies of categorical variables and the median values with interquartile ranges of continuous variables. Patient characteristics and outcomes were described between groups and compared using the $\chi^{2}$ and Wilcoxon rank sum tests where appropriate. Due to the descriptive nature of this study, multivariable analyses were not undertaken. It is known that several key anatomic and physiologic variables that may influence outcome in this patient population are not currently collected in the STS-CHSD, thus limiting the utility and results of multivariable modeling to attempt to identify independent risk factors for adverse outcomes. All analyses were performed using SAS version 9.3 (SAS Institute, Inc, Cary, NC). A $P$ value $<.05$ was considered statistically significant.

\section{RESULTS \\ Patient Population}

The cohort included 2399 patients over the 4 years of data collection (Table 1). Overall, $43 \%(n=1040)$ of patients were male and $78 \%(\mathrm{n}=1882)$ had Down syndrome.

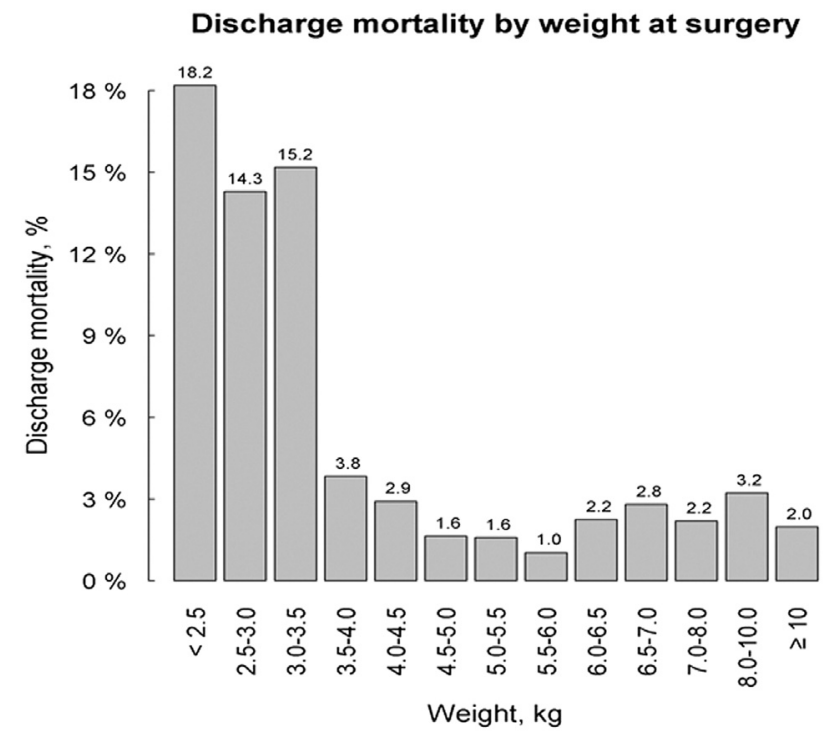

FIGURE 1. Discharge mortality by weight at surgery for the entire cohort of patients undergoing repair of complete atrioventricular septal defect during the period 2008 to 2011 . 
TABLE 1. Study population characteristics for the combined overall cohort and for those with or without Down syndrome

\begin{tabular}{|c|c|c|c|c|}
\hline Characteristic & Overall $(\mathbf{N}=2399)$ & $\begin{array}{l}\text { Down syndrome } \\
\quad(\mathrm{n}=\mathbf{1 8 8 2})\end{array}$ & $\begin{array}{l}\text { Non-Down syndrome } \\
\qquad(\mathrm{n}=\mathbf{5 1 7})\end{array}$ & $P$ value \\
\hline Age, d & $138.0(104.0$ to 182.0$)$ & $137.0(106.0$ to 176.0$)$ & $143.0(95.0$ to 225.0$)$ & .0432 \\
\hline Weight, kg & $5.0(4.3$ to 5.8$)$ & $5.0(4.3$ to 5.7$)$ & $5.0(4.2$ to 6.6$)$ & .0048 \\
\hline Weight for age $z$-score & $-2.3(-3.1$ to -1.5$)$ & $-2.3(-3.1$ to -1.5$)$ & $-2.0(-2.8$ to -1.3$)$ & $<.0001$ \\
\hline Male gender & $1040(43.4)$ & $830(44.1)$ & $210(40.6)$ & .1585 \\
\hline Antenatal diagnosis of congenital heart disease & $782(32.6)$ & $648(34.4)$ & $134(25.9)$ & .0001 \\
\hline Surgery year & & & & .0250 \\
\hline 2008 & $595(24.8)$ & $449(23.9)$ & $146(28.2)$ & \\
\hline 2009 & $651(27.1)$ & $524(27.8)$ & $127(24.6)$ & \\
\hline 2010 & $535(22.3)$ & 407 (21.6) & $128(24.8)$ & \\
\hline 2011 & $618(25.8)$ & $502(26.7)$ & $116(22.4)$ & \\
\hline
\end{tabular}

Values are given as median (interquartile range) or $\mathrm{n}(\%)$.

One-third of all patients had antenatal diagnosis of CAVSD. This differed between Down syndrome and non-Down syndrome patients ( $34 \%$ vs $26 \%$, respectively; $P=.0001)$. Median age at surgery was 4.6 months (interquartile range [IQR], 3.5-6.1) with $11.8 \%(\mathrm{n}=284)$ aged $\leq 2.5$ months. Median weight at surgery was $5.0 \mathrm{~kg}$ (IQR, 4.3-5.8) with $6.3 \%(\mathrm{n}=151)$ weighing $<3.5 \mathrm{~kg}$. Noncardiac congenital anatomic abnormalities (coded in the STS-CHSD since 2010 ) were present in $4 \%$ of cases (43 out of 1099).

\section{Preoperative Factors}

Twenty-eight percent of all patients had $\geq 1$ of the 34 preoperative factors collected in the STS-CHSD. The most common preoperative factor was mechanical ventilatory support (Table 2). Compared with patients with Down syndrome, those without Down syndrome had a higher frequency of mechanical ventilatory support $(7 \%$ vs $4 \%$; $P=.0035)$ and preoperative seizures $(2 \%$ vs $1 \%$; $P<.01)$. Non-Down syndrome patients also had a higher frequency of the composite variable "any major preoperative factor" ( $7 \%$ vs $4 \% ; P=.0045)$. Overall, $9 \%$ of the cohort had undergone at least 1 major cardiothoracic operation before having complete repair of the CAVSD.

The prevalence of $\geq 1$ preoperative factors was greater in patients undergoing repair at age $\leq 2.5$ months $(36 \%$ vs $27 \%$, respectively; $P=.001$ ), as shown in Table 3 .
Likewise, the prevalence of $\geq 1$ of the major preoperative factors was also greater in patients undergoing repair at age $\leq 2.5$ months $(14 \%$ vs $4 \%$, respectively; $P<.0001)$, largely due to a higher frequency of preoperative mechanical ventilatory support $(14 \%$ vs $3 \% ; P<.0001)$. Patients who underwent CAVSD repair at age $\leq 2.5$ months had fewer prior cardiothoracic surgery procedures $(7.7 \%$ vs $11.1 \%$, respectively; $P<.0001$ ).

\section{Operative Variables}

Median cardiopulmonary bypass time was 126 minutes (IQR, 98-161). Total crossclamp time was a median of 89 minutes (IQR, 68-116). Forty-six patients underwent circulatory arrest (median, 21 minutes; IQR, 9.0-30 minutes). There were no differences in cardiopulmonary bypass time (mean, $139 \pm 59$ minutes vs $135 \pm 56$ minutes) or crossclamp time (94 \pm 40 minutes vs $96 \pm 39$ minutes) by age group ( $\leq 2.5$ vs $>2.5$ months, respectively). Circulatory arrest was used in $6 \%$ of patients aged $\leq 2.5$ months and in $1.4 \%$ of patients aged $>2.5$ months $(P<.001)$. A variety of concomitant procedures were performed at the time of repair of the CAVSD, including a total of 122 patients $(4.6 \%)$ who underwent $\mathrm{PAB}$ removal at the time of the CAVSD repair (median age at CAVSD repair with PAB removal, 8.1 months; IQR, 5.6-13.8 months). Repair of coarctation or other aortic arch procedure was performed concomitantly with CAVSD repair

TABLE 2. Preoperative factors for the combined overall cohort and for those with or without Down syndrome

\begin{tabular}{|c|c|c|c|c|}
\hline Preoperative factor & $\begin{array}{c}\text { Overall } \\
(\mathbf{N}=\mathbf{2 3 9 9})\end{array}$ & $\begin{array}{c}\text { Down syndrome } \\
(\mathrm{n}=\mathbf{1 8 8 2})\end{array}$ & $\begin{array}{l}\text { Non-Down syndrome } \\
\qquad(\mathbf{n}=\mathbf{5 1 7})\end{array}$ & $P$ value \\
\hline Mechanical circulatory support* & $4(0.2)$ & $2(0.1)$ & $2(0.4)$ & .1662 \\
\hline Mechanical ventilatory support* & $110(4.6)$ & $74(3.9)$ & $36(7.0)$ & .0035 \\
\hline Renal dysfunction* & $4(0.2)$ & $3(0.2)$ & $1(0.2)$ & .8667 \\
\hline Shock - persistent* & $0(0)$ & $0(0)$ & $0(0)$ & NA \\
\hline Seizures & $29(1.2)$ & $17(0.9)$ & $12(2.3)$ & .0090 \\
\hline Septicemia & $21(0.9)$ & $15(0.8)$ & $6(1.2)$ & .4320 \\
\hline Any major preoperative factors & $115(4.8)$ & $78(4.1)$ & $37(7.2)$ & .0045 \\
\hline Any Society of Thoracic Surgeons preoperative factors & $667(27.8)$ & $517(27.5)$ & $150(29.0)$ & .4881 \\
\hline
\end{tabular}

Values are given as $\mathrm{n}(\%) . N A$, Not available. *Individual preoperative factor included in "Any major preoperative factors." 
TABLE 3. Preoperative factors for the combined overall cohort and for those with age at surgery $\leq 2.5$ months or $>2.5$ months

\begin{tabular}{|c|c|c|c|c|}
\hline Preoperative factor & $\begin{array}{c}\text { Overall } \\
(\mathbf{N}=\mathbf{2 3 9 9})\end{array}$ & $\begin{array}{c}\text { Age at surgery } \\
\leq 2.5 \mathrm{mo}(\mathrm{n}=284)\end{array}$ & $\begin{array}{c}\text { Age at surgery } \\
>2.5 \mathrm{mo}(\mathrm{n}=2115)\end{array}$ & $P$ value \\
\hline Mechanical circulatory support* & $4(0.2)$ & $3(1.1)$ & $1(0.0)$ & $<.0001$ \\
\hline Mechanical ventilatory support* & $110(4.6)$ & 39 (13.7) & $71(3.4)$ & $<.0001$ \\
\hline Renal dysfunction* & $4(0.2)$ & $1(0.4)$ & $3(0.1)$ & .4149 \\
\hline Shock-persistent* & $0(0)$ & $0(0)$ & $0(0)$ & NA \\
\hline Seizures & $29(1.2)$ & $2(0.7)$ & $27(1.3)$ & .4073 \\
\hline Septicemia & $21(0.9)$ & $2(0.7)$ & $19(0.9)$ & .7416 \\
\hline Any major preoperative factors & $115(4.8)$ & $40(14.1)$ & $75(3.5)$ & $<.0001$ \\
\hline Any Society of Thoracic & $667(27.8)$ & $102(35.9)$ & $565(26.7)$ & .0012 \\
\hline
\end{tabular}

Surgeons preoperative factors

Values are given as n (\%). NA, Not available. *Indicates individual preoperative factors included in "Any major preoperative factors."

in $1.6 \%(n=39)$ of the entire cohort, and was evenly distributed among those older or younger than age 2.5 months. Approximately one-third of patients had concomitant closure of a patent arterial duct and one-third had closure of an additional interatrial communication.

\section{In-Hospital Mortality}

Overall discharge mortality was $3.0 \%$. Table 4 summarizes associations between discharge mortality and weight at surgery, age at surgery, and presence or absence of Down syndrome. Patients at extremes of low weight and age had worse outcomes. Discharge mortality was higher among those without Down syndrome than among those with Down syndrome $(4.4 \%$ vs $2.6 \%$, respectively; $P=.03)$. For the 122 patients who underwent PAB removal at the time of CAVSD repair, discharge mortality was $4.1 \%$ (5 deaths).

\section{Postoperative Complications and Length of Stay}

Of the entire cohort, $50 \%$ of patients experienced $\geq 1$ complications as coded in STS-CHSD (exclusive of intraoperative death and sternum left open), and $9.8 \%$ of patients experienced $\geq 1$ of the 6 major complications included in the STS Congenital Heart Surgery Morbidity Score. ${ }^{14}$ Table 4 summarizes the frequency of occurrence of $\geq 1$ major complications and of reoperations with cardiopulmonary bypass after repair of CAVSD and during the same hospital admission across patient groups stratified by weight at surgery, age at surgery, and presence or absence of Down syndrome. Weight $<3.5 \mathrm{~kg}$ and age $\leq 2.5$ months were both associated with higher rates of discharge mortality, longer PLOS, and higher frequency of occurrence of major complications. Patients with Down syndrome had lower rates of major complications than those without Down syndrome. PLOS was similar for both groups. Frequency of reoperations with cardiopulmonary bypass during the same admission was unrelated to weight at surgery, but was higher in the younger age group ( $\leq 2.5$ months) and among those without Down syndrome. Although $12.1 \%$ of the entire cohort was reported to require temporary pacing for arrhythmia, only $2.7 \%$ underwent permanent pacemaker implantation either concomitantly or subsequent to repair

TABLE 4. Distributions of outcomes by patient factors

\begin{tabular}{|c|c|c|c|c|c|}
\hline & $\begin{array}{l}\text { Frequency, } \\
\text { n (\%) }\end{array}$ & $\begin{array}{c}\text { In-hospital } \\
\text { mortality }(\%)\end{array}$ & $\begin{array}{l}\text { Postoperative length of } \\
\text { stay (median, IQR) }\end{array}$ & $\begin{array}{l}\text { Complications ( } \% \text {, with } 1 \text { or } \\
\text { more major complications } * \text { ) }\end{array}$ & $\begin{array}{c}\text { Reoperations with } \\
\text { cardiopulmonary bypass } \\
\text { before discharge }(\%)\end{array}$ \\
\hline \multicolumn{6}{|c|}{ Weight at surgery } \\
\hline$<3.5 \mathrm{~kg}$ & $151(6.3)$ & 15.2 & $14(8-32)$ & 16.6 & 4.0 \\
\hline$\geq 3.5 \mathrm{~kg}$ & 2247 (93.7) & 2.2 & $8(5-14)$ & 9.4 & 3.0 \\
\hline$P$ value & - & $<.0001$ & $<.0001$ & $<.01$ & .49 \\
\hline \multicolumn{6}{|c|}{ Age at surgery } \\
\hline$\leq 2.5 \mathrm{mo}$ & $284(11.8)$ & 9.5 & $12(8-25)$ & 13.4 & 7.0 \\
\hline$>2.5 \mathrm{mo}$ & $2115(88.2)$ & 2.1 & $7(5-13)$ & 9.4 & 2.5 \\
\hline$P$ value & - & $<.0001$ & $<.0001$ & .03 & $<.0001$ \\
\hline \multicolumn{6}{|c|}{ Down syndrome } \\
\hline No & 517 (21.6) & 4.4 & $8(5-16)$ & 15.1 & 5.4 \\
\hline Yes & $1882(78.4)$ & 2.6 & $8(6-14)$ & 8.4 & 2.4 \\
\hline$P$ value & - & .03 & .34 & $<.0001$ & $<.001$ \\
\hline Overall & $2399(100)$ & 3.0 & $8(5-14)$ & 9.8 & 3.0 \\
\hline
\end{tabular}

$I Q R$, Interquartile range. $*$ Major complications include renal failure requiring dialysis, neurologic deficit persisting at discharge, atrioventricular block/arrhythmia requiring permanent pacemaker, postoperative mechanical circulatory support, phrenic nerve injury, and unplanned reoperations. 
of CAVSD. There was no difference in proportion of patients with heart block requiring a permanent pacer relative to the presence of Down syndrome or the age at operation. Reoperation for postoperative bleeding occurred in $1.3 \%$ of cases. Approximately $3 \%$ of patients underwent an additional subsequent procedure requiring cardiopulmonary bypass during the same admission, whereas $8 \%$ had a procedure not requiring cardiopulmonary bypass.

\section{Comments}

We report early outcomes of CAVSD repair across a large multicenter cohort, providing a contemporary snapshot of practices at centers in North America and shedding light on associations of outcomes with such factors as extremes of low weight and age and Down syndrome. Overall inhospital mortality of $3 \%$ is consistent with rates reported recently from individual centers and from a PHN multicenter study that included data from 7 institutions. ${ }^{7,9}$

Given the prevalence of Down syndrome among patients with CAVSD, an understanding of associations between this genetic syndrome and outcomes is important. Evans and colleagues ${ }^{15}$ recently reported an analysis of administrative data (Kids' Inpatient Database) that evaluated the association between Down syndrome and in-hospital death among children undergoing surgery for congenital heart disease. These investigators found that children with Down syndrome who underwent repair of congenital heart disease were more likely to survive to discharge than children without Down syndrome. Although their cohort was large, and they analyzed outcomes across the strata of procedural risk defined by Risk Adjustment for Congenital Heart Surgery classification levels, they did not evaluate specific diagnostic or procedural groups and offered no data or inferences related to repair of CAVSD. Our study does provide this additional specific information.

To varying degrees, management of infants with CAVSD and Down syndrome has, in the past, been influenced by many assumptions concerning pulmonary function, airway and vascular reactivity, and predisposition to various morbidities. Our data clearly attest to lower overall hospital mortality, fewer major complications, and fewer reoperations with bypass before discharge among Down syndrome patients. In addition, their PLOS is not different from that of patients without Down syndrome. An often described observation is that patients with CAVSD and Down syndrome have less variability in the morphology of the common atrioventricular valve than do patients without Down syndrome. If so, this may have a favorable influence on the physiologic results after repair. If this is true in our STS-CHSD cohort could not be evaluated, because pertinent details concerning morphology are not captured in the database.

Whereas the age at which infants generally undergo CAVSD repair has declined significantly during the past few decades, ideal timing of repair is still debated. ${ }^{6,8-11}$ One of the important goals of early repair is to prevent the development of irreversible pulmonary vascular disease, which can be found as early as age 6 months. ${ }^{16}$ Additional benefits of early repair include decreasing the risk of developing degenerative changes, including thickening of the common atrioventricular valve and decreasing the risk of prolonged failure to thrive. ${ }^{17,18}$ However, in very young infants, fragility of the common atrioventricular valve tissue may increase the technical challenge. Most published reports favor early repair and define early repair as younger than age 6 months. ${ }^{6-8,10}$ There is a paucity of literature analyzing the risks and benefits of repair at a very young age such as 1 to 3 months.

In our study, $11.8 \%$ of patients $(\mathrm{n}=284)$ underwent surgery at age $\leq 2.5$ months. These patients had worse outcomes with higher rates of discharge mortality, longer PLOS, and higher frequency of occurrence of $\geq 1$ major complications. In addition, frequency of reoperations with cardiopulmonary bypass was higher in this younger cohort. These data add to the findings of a smaller PHN study in which Atz and colleagues ${ }^{9}$ noted that repair at age $\leq 2.5$ months was associated with longer hospital stay, longer intensive care unit stay, longer ventilator use, and greater complication rates. They also noted a trend toward greater mortality by age 6 months and greater need for reoperation within the first 6 months. Given the small size of their cohort, the number of in-hospital deaths was too small to empower a statistically meaningful analysis.

Several reports have explored associations between age at surgery, weight at surgery, and outcomes. Weight and age are closely related, but not necessarily as consistently or predictably in patients with CAVSD as in infants without congenital heart disease. Congestive heart failure and pulmonary artery hypertension are associated with feeding difficulties, abnormal energy expenditure, and failure to thrive. Waiting for weight gain can be a risky and unpredictable strategy. Prifti and colleagues ${ }^{19}$ explored associations between weight and postoperative outcomes of CAVSD repair and noted that weight $<5 \mathrm{~kg}$ at the time of repair (median age, 4.3 months) was associated with a high rate of late reoperation for left atrioventricular valve regurgitation. In contrast, Suzuki and colleagues ${ }^{5}$ reported a higher incidence of preoperative left atrioventricular valve regurgitation in infants who underwent repair at age $<3$ months, but no difference in postoperative residual regurgitation or reoperation for left atrioventricular valve dysfunction. Similarly, Reddy and colleagues ${ }^{20}$ reported on a series of 72 infants with repair at median age of 3.9 months $(40 \%<3$ months) and concluded that age at repair does not influence outcome or valve function. With the exception of the study by Atz and colleagues, ${ }^{9}$ the above-mentioned reports all describe single institution experiences that reflect 
individual centers' surgical technique and postoperative management.

\section{Limitations}

This descriptive analysis is based on a very large multiinstitutional cohort and provides important information about current patterns of practice as well as benchmark data concerning early outcomes. The study results must, however, be interpreted with caution. The preoperative data fields in the STS-CHSD at the time of the study lacked sufficient granularity to support development of multivariable risk models that might guide surgical decision making. At the time of our study the database did not gather information regarding specific morphologic and physiologic details and procedural variables related to CAVSD repair that may be related to timing of surgery and to outcomes. Specifically, before 2014, database fields did not include degree of preoperative atrioventricular valve regurgitation, morphology of common atrioventricular valve (eg, single left-sided papillary muscle, deficient mural leaflet, or double orifice), ventricular imbalance, and other patient-specific factors that may be related to the risk of poor outcomes, such as degree of atrioventricular valve regurgitation. For a multivariable risk factor analysis to be informative, it would be necessary to include such variables. Based only on the data currently available in the STS Database, it is not possible to ascertain if some individual patients had surgery very early in infancy or at very low weight because of unfavorable morphology, an extreme degree of physiologic compromise, or other reasons. Additional fields that relate specifically to repair of CAVSD have recently been added to the STS-CHSD. These pertain to degree of preoperative atrioventricular valve regurgitation; malalignment or unbalance of the defect and the common atrioventricular valve; and other surgically relevant morphologic details such as single papillary muscle, deficient posterior mural leaflet, and double orifice left atrioventricular valve.

\section{CONCLUSIONS}

In a large contemporary multicenter cohort, most patients with CAVSD underwent operation early during the first year of life. Mortality and major complication rates are lower for patients with Down syndrome than for those without. Although overall mortality is generally low for the entire cohort of patients undergoing repair of CAVSD, patients at extremes of low weight and age have worse outcomes. Incorporation into the STS-CHSD in 2014 of a complement of fields pertaining specifically to repair of CAVSD may facilitate risk stratification of these challenging patients.

\section{References}

1. Jacobs JP, Jacobs ML, Mavroudis C, Chai P, Tchervenkov C, Lacour-Gayet F, et al. Atrioventricular septal defects: lessons learned about patterns of practice and outcomes from the Congenital Heart Surgery Database of the Society of Thoracic Surgeons. World J Pediatr Congenit Heart Surg. 2010;1:68-77.

2. Hoohenkerk GJ, Bruggemans EF, Rijlaarsdam M, Schoof P, Koolbergen D, Hazekamp M. More than 30 years' experience with surgical correction of atrioventricular canal defects. Ann Thorac Surg. 2010;90:1554-61.

3. Ono M, Goerler H, Boethig D, Betram H, Westhoff-Bleck M, Haverich A, et al. Improved results after repair of complete atrioventricular septal defect. J Card Surg. 2009;24:732-7.

4. Bando K, Turrentine MW, Sun K, Sharp T, Ensing G, Miller A, et al. Surgica management of complete atrioventricular septal defects. A twenty-year experience. J Thorac Cardiovasc Surg. 1995;110:1543-4.

5. Suzuki T, Bove EL, Devaney EJ, Ishizaka T, Goldberg C, Hirsch J, et al. Results of definitive repair of complete atrioventricular septal defect in neonates and infants. Ann Thorac Surg. 2008;86:596-602.

6. Crawford FA Jr, Stroud MR. Surgical repair of complete atrioventricular septal defect. Ann Thorac Surg. 2001;72:1621-9.

7. Tweddel JS, Litwin SB, Berger S, Friedberg D, Thomas J, Frommelt P, et al. Twenty-year experience with repair of complete atrioventricular septal defects Ann Thorac Surg. 1996;62:419-24.

8. Günther T, Mazzitelli D, Haehnel CJ, Holper K, Sebening F, Meisner H. Longterm results after repair of complete atrioventricular canal defects: analysis of risk factors. Ann Thorac Surg. 1998;65:759-60.

9. Atz AM, Hawkins JA, Lu M, Cohen M, Colan S, Jaggers J, et al. Surgical management of complete atrioventricular septal defect: associations with surgical technique, age, and trisomy 21. J Thorac Cardiovasc Surg. 2011;141:1371-9.

10. Bakhtiary F, Takacs J, Cho MY, Razek V, Dahnert I, Doenst T, et al. Long-term results after repair of complete atrioventricular septal defect with two-patch technique. Ann Thorac Surg. 2010;89:1239-43.

11. Singh RR, Warren PS, Reece TB, Peeler BB, Kron IL. Early repair of complete atrioventricular septal defect is safe and effective. Ann Thorac Surg. 2006;82: 1598-601.

12. Kaza AK, Colan SD, Jaggers J, Lu M, Atz A, Sleeper LA, et al. Surgical interventions for atrioventricular septal defect subtypes: the pediatric heart network experience. Ann Thorac Surg. 2011;92:1468-75.

13. Fudge JC Jr, Li S, Jaggers J, O’Brien S, Peterson E, Jacobs J, et al. Congenita heart surgery outcomes in Down syndrome: analysis of a national clinical database. Pediatrics. 2010;126:315-22.

14. Jacobs ML, O’Brien SM, Jacobs JP, Mavroudis C, Lacour-Gayet F, Pasquali S, et al An empirically based tool for analyzing morbidity associated with operations for congenital Heart Disease. J Thorac Cardiovasc Surg. 2013;145:1046-57.

15. Evans JM, Dharmar M, Meierhenry E, Marcin JP, Raff GW. Association between Down syndrome and in-hospital death among children undergoing surgery for congenital heart disease: a US population-based study. Circ Cardiovasc Qual Outcomes. 2014;7:445-52.

16. Newfeld EA, Sher M, Paul MH, Nikaidoh H. Pulmonary vascular disease in complete atrioventricular canal defect. Am J Cardiol. 1977;39:721-6.

17. Yasui H, Nakamura Y, Kado H, Yonenga K, Shiokawa Y, Fusazaki N, et al. Primary repair for complete atrioventricular canal: recommendation for early primary repair. J Cardiovasc Surg (Torino). 1990;34:498-504.

18. Mavroudis C, Weinstein G, Turley K, Ebert PA. Surgical management of complete atrioventricular canal. J Thorac Cardiovasc Surg. 1982;83:670-9.

19. Prifti E, Bonacchi M, Bernabei M, Crucean A, Murzi B, Bartolozzi F, et al Repair of complete atrioventricular septal defects in patients weighing less than 5 kg. Ann Thorac Surg. 2004;77:1717-26.

20. Reddy VM, McElhinney DB, Brook MM, Parry AJ, Hanley FL. Atrioventricular valve function after single patch repair of complete atrioventricular septal defect in infancy: how early should repair be attempted? J Thorac Cardiovasc Surg. 1998;115:1032-40 